\title{
STUDY OF LEGAL FRAMEWORK OF INVOLVEMENT OF NURSES IN THE PROCESS OF PATIENT'S INFORMED CONSENT IN THE REPUBLIC OF BULGARIA AND OTHER COUNTRIES
}

\author{
Anna Georgieva ${ }^{1}$, Maria Valkanova ${ }^{2}$ \\ ${ }^{1}$ Department of Nursing Care, Faculty of Public Health, ${ }^{2}$ Department of Social Medicine \\ and Organization of Healthcare, Faculty of Public Health, Medical University of Varna
}

\section{ABSTRACT}

INTRODUCTION: Essential in providing medical assistance to patients is achieving clarity and legal certainty in the work of medical professionals. To this end, a clear and uniform approach in regulation of involvement of nurses in the process of patient's informed consent, which is currently lacking in the legislation of the Republic of Bulgaria, is to be adopted.

OBJECTIVE: To examine the legal framework of the involvement of nurses in the process of patients' informed consent in the Republic of Bulgaria and other countries.

MATERIALS AND METHODS: We have applied a documentary method. A comparative legal analysis of the legislation on the involvement of nurses in the process of patients' informed consent in the Republic of Bulgaria and other countries within the period January 2014 - May 2015 has been made.

DELIVERABLES: Based on the comparative legal analysis of the legislation of the Republic of Bulgaria and the countries studied, it was found that there is no single approach to the regulations of the involvement of nurses in the process of patients' informed consent in the country unlike the laws of other countries where it is clearly and systematically arranged.

DISCUSSION: In the laws that have been reviewed the liability to inform patients lies on all health professionals. According to the analyzed legal definitions in the legal sources compared, a nurse is a health professional and as such, she has certain obligations in the process of informed consent of patients.

CONCLUSION: It is necessary the current Bulgarian legislation on the involvement of nurses in the process of patients' informed consent to be further developed and refined taking into account the experience of other countries.

Keywords: nurse, informed consent, legal regulation, patient

Address for correspondence:

Anna Georgieva

Department of Nursing Care,

Faculty of Public Health,

Medical University of Varna

55 Marin Drinov Str.

9002 Varna, Bulgaria

e-mail:anngebg@gmail.com

Received: November 5, 2015

Accepted: December 1, 2015

\section{INTRODUCTION}

Essential in providing medical assistance to patients is achieving clarity and legal certainty in the work of medical professionals.

To this end, a clear and uniform approach in the regulation of the involvement of nurses in the process of patient's informed consent is to be adopted.

The OBJECTIVE of this study is to examine the legal framework of the involvement of nurses in 
the process of patients' informed consent in the Republic of Bulgaria and other countries.

\section{MATERIALS AND METHODS}

We have performed a systematic comparative analysis of legal documents on the involvement of nurses in the process of obtaining patients' informed consent in the Republic of Bulgaria and other countries within the period January 2014 - May 2015.

\section{DELIVERABLES}

\section{Legislation in the Republic of Bulgaria}

In the current legislation, the obligation to inform the patient and obtain his/her consent is regulated in the Health Act. In pursuance of Article 88, para 1 of the Health Act: "In order to obtain the informed consent, the physician (doctor of dental medicine) in charge of the treatment shall inform the patient or the parent, custodian or trustee respectively, as well as the persons under Article 162, Paragraph 3 about:

1. the diagnosis and nature of the disease;

2. the description of the goals and the nature of the treatment, the reasonable alternatives, the expected outcome and the prognosis;

3. the potential risks related to the proposed methods of diagnostics and treatment, including the side effects and undesired pharmaceutical reactions, pain and other discomfort;

4. the likelihood of a favorable impact, and the health risk in the application of other methods of treatment or in the refusal to take treatment."

However, in the Health Act there are no texts that specifically govern the involvement of nurses in the process of informing and obtaining patient's consent (1).

As evident by the provision of Article 87, para 1 of the Health Act, "Medical activities shall be performed upon the informed consent expressed by the patient" (1). Or a consent is given to perform a specific medical procedure. The provisions on the informed consent are given in section "Patient's Rights and Obligations". According to Article 84, para 1 of the Health Act a patient is any person who has sought or who is receiving medical aid (1). Therefore, the provisions of the informed consents are applied always and only when it comes to treatment and providing medical care (2). Therefore, the performance of any medical provision without consent will be illegal. This is the meaning of the sanction provision of Article 220, para 2 of the Health Act, namely: "Officials failing to inform the patient of the circumstances under Article 88, Paragraph 1 shall be punished with a fine ranging from BGN 300 to BGN 1000 and with withdrawal of the right to exercise the medical profession for a term ranging from six months to a year in the case of repeated violation" (1).

In this case under the term "official" according to the text of Article 88, para 1 of the Health Act, the legislator is apparently referring to the doctor since the obligation to inform under Article 88 of the Health Act is imposed on him/her (1).

At the same time, as already stated, persons providing medical aid without the informed consent of the patient or in violation of the requirements for obtaining the informed consent of the patient shall be punished with a fine ranging from BGN 500 to BGN 1500 and with withdrawal of the right to exercise the medical profession for a term ranging from six months to a year in the case of repeated violation (Article 220 para 2 of the Health Act) (1).

Then, the question of to whom the penalties cited in this provision are addressed could justifiably be raised, since the medical aid is provided only by doctors. The answer should be sought in the clarification of the term "medical aid". However, there is no legal definition of this term in the Health Act. Meanwhile, the Health Insurance Act provides a legal definition of the term "medical aid" according to which this is a system of diagnostic, treatment, rehabilitation and prevention activities, provided by medical specialists (argument of $₫ 1$, Item 9, Additional provisions to the Health Insurance Act).

And according to $\$ 1 \mathrm{~b}$, Item 5 of the Additional provisions of the Health Insurance Act, "medical specialists" are persons, exercising the medical profession under Article 183, para 1 of the Health Act (3).

Consequently, "medical aid" is provided by persons, practicing medical profession under Article 183, para 1 of the Health Act, i.e. persons who hold a diploma for completed higher education in specialties from the occupational sections of medicine, dentistry, pharmacology and health care, to whom ap- 
parently nurses belong as per the provision of Article 183, para 4 of the Health Act.

In this case, the provision of Article 220 para 1 of the Health Act refers also to nurses as part of the subject providing medical aid.

Moreover, according to Article 3, para 1 Item 1 of Ordinance No 1 of 8 February 2011 on professional activities which the nurses, midwives, associated medical specialists and health assistants can carry out upon instruction or independently, are: provision and collection of health information, including informing patients to obtain informed consent in carrying out tests and manipulations (4).

Hence, according to the secondary legislation, the nurse is subject to the obligation to obtain consent and to inform. However, it is unclear why the legislature has imposed the said obligation only to the doctor in the provision of Article 88 of the Health Act, according to which "In order to obtain the informed consent, the physician (doctor of dental medicine) in charge of the treatment shall inform the patient or the parent, custodian or trustee respectively, the person under Article 87, para 5, the provision of Article 87, para 6 as well as the persons under Article 162, Paragraph 3, omitting the involvement of the nurse in the process (1).

In this connection it should be added that a significant part of the manipulations performed by the nurse have the so called invasive nature within the meaning of $₫ 1$, Item 3 of the Additional provisions of the Health Act (1). Therefore, they require written consent and, moreover, it is a condition for the reality and validity of the consent in the case. It could have been difficult to assume that for these manipulations, carried out by nurses, the consent is to be obtained by the doctor. Information regarding the consent is provided by the competent medical specialist, who is in charge of its implementation and is responsible for it.

The results of the legal analysis of the legislation of the Republic of Bulgaria on the issue of the involvement of nurses in the process of informing and obtaining the consent of the patient demonstrate that in this regard the effective legislation requires further elaboration and refinement.

This necessitates examining the other countries' experience in the legal regulation of the in- volvement of nurses in the process of patients' informed consent.

\section{Legislation in Denmark}

In the Health Act of Denmark, $₫ 15$ Article 3, the legislature introduces a legal definition of the term "informed consent", according to which "Informed consent as defined in this Act is a consent given on the basis of sufficient information from a health professional" (5).

Within the meaning of this Act "Health professionals means persons authorized by special legislation - Law on authorization procedures for health professions and health practice (consolidation act No 877, 04.08.2011, Ministry of Health) to carry out health care services, and persons acting on their responsibility"( $\$ 6$ of the Health Act of Denmark) (5).

According to the Law on authorization procedures for health professions and health practice (consolidation act No 877, 04.08.2011, Ministry of Health) the nurse is among the persons practicing health professions and "The right to the title of nurse has only the one who has certification as a nurse" (Chapter 13, $\$ 54$, Article 2) (6).

Therefore, according to Danish legislation, the nurse is a health professional and as such she has certain obligations in the process of patient's informed consent.

Belgium and Finland have chosen similar legislative solution:

According to the Belgian Law of 22 August 2002 on Patient's Rights: “The patient has the right to freely consent to any intervention of the professional practitioner if notified in advance." (Article 8, \$1) (7). The Belgian Law on Patient's Rights provides that: „professional practitioner (praticien professionnel)" is the practitioner referred to in Royal Decree No. 78 of 10 November 1967 on the practice of professions in health care." (Chapter II. Article 2, \$3). According to Article 21, $\$ 1$ of the said Royal Decree "No person may practice the art of nursing if it is not a holder of a diploma for nursing" (8).

According to the Act on the status and rights of patients No 785/1992 of Finland: "A patient shall be given information about his/her state of health, the significance of the treatment..., and about other factors related to his/her treatment that are significant when decisions are made on the treatment given to 
him/her "(Section 5, \$2). "Health care professionals should try to give the information in such a way that the patient can understand it" (Section 5, \$2) (9).

According to the Act on the status and rights of patients No 785/1992 of Finland, the term "health care professionals" refers to persons, specified in Section 2 of the Health Care Professionals Act (559/1994) (Section 5, Item 3) $(9,10)$. The Health Care Professionals Act (559/1994) also regulates the practicing of nursing profession (10).

Hence, the nurse is a health professional and as such she has certain obligations in the process of patient's informed consent.

\section{Legislation in France}

According to the Public Health Code, Chapter One: „everyone has the right to be informed about his medical condition (Article L1111-2) (11). The obligation of information rests on every professional taking into account his professional competences and the professional rules which apply to him. Only the emergency of the individual case and the impossibility to inform dismiss of this obligation." (again Article L1111-2) (11).

The status of nurses is detailed in Part Four of the Public Health Code: Professions in the Field of Health Care (11).

Hence, it can be concluded that the French legislature assigns nurses to health care professionals and all the provisions in the Public Health Code of France, referring to health care professionals, including the rules on consent, apply also to nurses.

\section{Legislation in Spain}

According to Law 41/2002, of 14 November, regulating the patient's autonomy and rights and obligations of clinical information and documentation: "Every action in the field of health requires, in general, the prior consent of patients or users. The consent must be obtained after the patient receives adequate information shall be in writing in the cases provided for in the Act (Section 2. \$2) (12).

„Every professional involved in the care activity is required not only to provide the correct techniques, but the execution of the duties of information and clinical documentation, and respect for the free and voluntary decisions taken by the patient " (Section 2. \$6) (12).
According to Law 41/2002, of 14 November, regulating the patients autonomy and rights and obligations of clinical information and documentation the "Clinical information is part of all care proceedings, be true, be communicated the patient in an understandable and appropriate to their needs and will help you make decisions according to their own free will ”(Section 4, \$6) (12).

„The attending physician ensures compliance of their right to information. Professionals who meet him for the care process or you apply a technique or a specific procedure will also be responsible for informing" (Section 4, §3) (12).

Consequently, the nurse, as a medical specialist providing care during the process of treatment of patients, according to the Spanish legislature, is also responsible for informing patients.

\section{DISCUSSION}

In the laws that have been reviewed the liability to inform patients lies on all health professionals. According to the analyzed legal definitions in the legal sources compared, a nurse is a health professional and as such, she has certain obligations in the process of informed consent of patients.

\section{CONCLUSION}

It is necessary the current Bulgarian legislation on the involvement of nurses in the process of patients' informed consent to be further developed and refined taking into account the experience of other countries. This will contribute to better ensure the patient's right of self-determination and will protect nurses in the performance of her professional duties.

\section{REFERENCES}

1. Health Act- SG No 103 of 23 December 2005, last amended and supplemented SG No 1 of 3 January 2014. Bulgarian.

2. Valkanova M. Medical Law. $1^{\text {st }}$ ed. Varna: Steno; 2014. Bulgarian.

3. Health Insurance Act, promulgated SG No 70 of 19 June 1998, last amended SG No 12 of 13 February 2015. Bulgarian.

4. Ordinance No 1 of 8 February 2011 on professional activities which the nurses, midwives, associated medical specialists and health assistants can carry out upon instruction or independently, issued 
by the Ministry of Health, promulgated SG No 15 of 18 February 2011, amended SG No 50 of 1 July 2011. Bulgarian.

5. Consolidation Act No. 877 of 4 August 2011 on Authorization of Health Care Professionals and on Professional Health Care Practice, Publication date: 09-08-2011, Ministry of Health, Denmark. Available from: https://www.retsinformation.dk/forms/ r0710. aspx?id=13817. Danish.

6. Consolidation Act No. 913 of 07.13.2010 Applicable (Health Act).

Publication Date: 15-07-2010, Ministry of Health, Denmark. Available from: https://www.retsinformation.dk/forms/r0710.aspx?id=130455. Danish.

7. Law of 22 August 2002 on the Rights of Patients, Belgian Official Gazette, 26.09.2002, Ed. 2, Ministry of Social Affairs of Public Health and the Environment F. 2002 - 3341. Available from: http://www.soinspalliatifs.be/images/pdf/ loi_2002_08_22.pdf. French.

8. Royal Decree No 78 of 10 November. 1967 on the practice of the healthcare professions, http://health. belgium.be/eportal. French.

9. Act on the status and rights of patients No. 785/1992, issued in Helsinki on $17^{\text {Th }}$ August 1992, Ministry of Social Affairs and Health, Finland. Available from: http://www.finlex.fi/en/laki/kaannokset/1992/en19920785.pdf

10. Health Care Professionals Act No. 559/1994, issued in Naantali on 28 June 1994, (last amendet 2011), Ministry of Social Affairs and Health, Finland. Available from: http://www.finlex.fi/fi/laki/kaannokset/1994/en19940559.pdf.

11. Public Health Code, Consolidated Version 27 March 2014 Last Updated: March 27, 2014. http:// www.legifrance.gouv.fr/affichCode.do?cidTexte $=\mathrm{L}$ EGITEXT000006072665. French.

12. Law $41 / 2002$, of 14 November, regulating patient autonomy and rights and obligations of clinical information and documentation. Published in: BOE no. 274 of 15 November 2002, pp. 40126-40132 (7 p.) Section: I. General Provisions, Department: Head of State, Reference: BOE-A-2002-22188. Available from: http://www.boe.es/boe/ dias/2002/11/15/pdfs/A40126-40132.pdf. Spanish. 